\title{
INTERNATIONAL YEAR OF THE OLDER PERSONS
}

W That does it mean 'to grow old gracefully?' I consulted the Oxford Dictionary pleasing, attractive especially in form, movement or action". May I suggest posture, movement and function as more appropriate. This definition will surely make every physiotherapist sit up and think! You will ponder not only from a professional point of view but also from a personal point of view, for if it does not apply to you now, you will surely be 'there' one day. How can a person be graceful if they are bent, stiff and in pain?

The papers presented in this journal cover most areas affecting the aging process. Cultural issues where different attitudes to aging are postulated, as well as psychosocial issues will provide insight into how people react to different situations. You will read about how all the systems of the body change as one gets older. Included must be the senses, especially hearing seeing and feeling. A commentator covering the tennis championships at Wimbledon confirmed this for me by stating that a 35-year old player would now be entering the veteran age.

Retirement often results in a change in lifestyle and there maybe a loss or diminished income. This may result in a loss of confidence and self-esteem and depression, which is not uncommon in aging. On the other hand motivated individuals may embark on a new career or have the time to pursue neglected hobbies. In the developed world people are often forced to retire early and the population over 65 is growing at a rate of $2.5 \%$ per year. However, the emergence of HIV/AIDS and its rapid proliferation will have a profound effect on these statistics. The United Nations Program on HIV/ AIDS and WHO reported 6 million new HIV infections in 1998. In sub Sahara Africa alone there were 5500 deaths from AIDS every day. They reported $20 \%-25 \%$ prevalence in HIV in four of these countries reducing life expectancy by as much as 17 years. A local newspaper reported a drop in the life expectancy from 64 years to 47 years in Zimbabwe. The impact of AIDS has been described as 'the greatest crises in the recorded history of Africa'. What are the implications of this statement?

Grandparents will have to care for the terminally ill at the same time as looking after their grandchildren. Government policy of changing the emphasis of health care from tertiary care to primary health care has now become a reality. Physiotherapists who have continually resolved to become more community orientated in primary health care have no alternative but to act now as posts in tertiary hospitals become frozen. It is in their own homes that the termi-

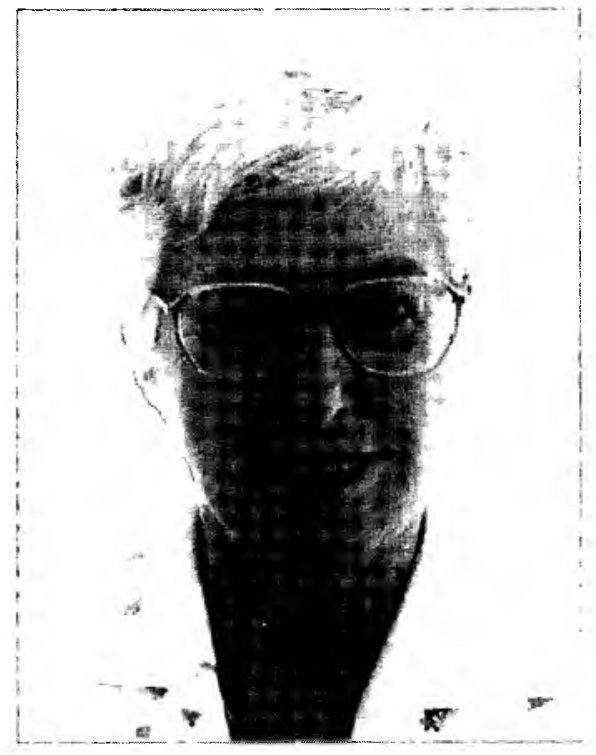

nally ill patient and their families and caregivers will need guidance and support from the professionals.

Generalizations about the characteristics of any age group must be made with caution. We know well that every human being is different. I quote from Dr Eales' paper 'The fact is that the longer we live the more different from each other we become because our life experiences are different."

We have much to learn from the older members of society if we choose to listen.

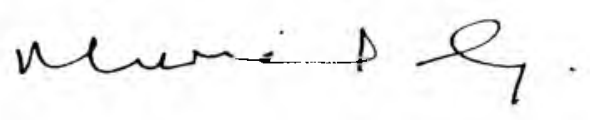

MURIEL GOODMAN EDITOR 